\title{
Video head impulse test finding in vestibular lesions
}

\begin{abstract}
Background and objective: Video head impulse test (vHIT) is a new test that provides information about each semicircular canal function by quantifying the gain of the VOR and it detects refixation saccades, overt and covert saccades. Our aims to compare video head impulse test results among different vestibular lesions and healthy subjects. To correlate between video head impulse test and caloric test results.
\end{abstract}

Methods: Case control study in which the control group included 30 normal healthy subjects. The study group included 62 patients suffering from dizziness. The study group subdivided into four subgroups vestibular neuritis (VN), Ménière's disease (MD), benign paroxysmal positional vertigo (BPPV) and central lesion subgroups. All subjects were submited to Videonystagmography (VNG) and vHIT.

Results: There was statistical significant difference in vHIT gain between VN subgroup \& control group. There was no significant difference in vHIT results between control and central lesion subgroup. There was strong negative correlation between caloric test and vHIT gain result in VN, but weak in other subgroups. Sensitivity and specificity of vHIT in VN were $84.21 \%$ and 63.33 respectively. In MD were 63.21 and $86.67 \%$ respectively.

Conclusion: increased sensitivity of vHIT to large unilateral peripheral vestibular lesions. Caloric testing was a more sensitive measure than vHIT in peripheral vestibular lesions but in central lesion they are almost equal. Strong negative correlation between caloric test (UW \%) and vHIT gain results in lateral SCC was found in VN lesion. It was weak in other vestibular lesions.

Keywords: vHIT, vestibular lesions, VNG
Volume II Issue I - 2019

\author{
Ismail N,' Behairy R,' Brakat D² \\ 'Audio-vestibular Medicine, Department of \\ Otorhinolaryngology, Audiovestibular Unite,Al-Azhar University, \\ Egypt \\ ${ }^{2}$ Department of Otorhinolaryngology, Ministry of Health, Egypt
}

Correspondence: Reda Mohamed Behairy, Lecturer of Audio-vestibular Medicine, Department of Otorhinolaryngology, Audiovestibular Unite, AL-Azhar University, Egypt,Tel 0I222739249, Email drredabehairy@yahoo.com

Received: December 18, 2018 | Published: January 09, 2019

\section{Introduction}

Introduction of video head impulse test (vHIT) as a new objective quantitative test of vestibular function, provides a new dimension in vestibular evaluation. ${ }^{1}$

vHIT is a simple fast clinical vestibular test. It has the ability to detect specific vestibular lesion by using physiologic high frequency stimuli and measure the gain of the vestibulo-occular reflex (VOR). If there is abnormal VOR response, the test can measure the gain of VOR and detect any refixation saccade (overt and covert saccades. ${ }^{2}$

The vestibular hair cells respond to frequencies from 0 to $16 \mathrm{~Hz}$, being particularly active in the range of $0.1-10 \mathrm{~Hz}$. The caloric test is usually in the area ranging from 0.003 to $0.05 \mathrm{~Hz}$, but rotational tests are in the area of high frequencies. ${ }^{3}$ The vHIT is a more physiological stimulus testing higher frequencies $(>1 \mathrm{~Hz})$ Heuberger et al. ${ }^{4}$ It is therefore possible that a subject may have a normal caloric test, but manifest VOR deficits during head movements within a higher frequency range. ${ }^{5}$

Bartolomeo et al., ${ }^{6}$ found the sensitivity of vHIT increased up to $86.7 \%$ and specificity to $100 \%$ when the caloric deficit is between 40 and $65 \%$ in case of VN. The sensitivity of vHIT increased to $100 \%$ if caloric deficit is more than $65.2 \%$. McCaslin et al., ${ }^{7}$ found dissociation between caloric test and vHIT in MD as caloric tests showed a vestibular deficit, while the vHIT was normal in $45 \%$ of the cases. Manzari et al., ${ }^{8}$ reported an enhanced vHIT lateral canal gain response in all 13 Meniere's patients tested at attack and in 18 of 30 patients tested during quiescence. Their hypothesis was that the enlarged endolymph volume causes enhanced displacement and enhanced return of the cupula which might lead to enhanced response in MD patients.

Caloric testing and the video head impulse test (vHIT) are reliable tests, caloric testing can evaluate the function of the lateral semicircular canal and superior vestibular nerve, However, vHIT can detect abnormalities in all six semicircular canals and it can be used in patients who do not tolerate caloric test such as some elder patient, children or patient with perforated tympanic membrane. ${ }^{9}$ The vHIT can be used as a screening tool for vestibular deficits due to gentamicin toxicity. ${ }^{10}$

The simplicity of vHIT and its relatively innocuous character for patients means that it can be used even during vertigo attacks. So it has been used to show in patients with Menière's disease how semicircular canal function fluctuates during and around the time of the attack of vertigo Manzari et al. ${ }^{8}$ Also there is need to have objective measure of the VOR during HIT by using a system fast enough and accurate enough to detect any type of saccades because some patients were missed by bedside head impulse test, even by expert examiners. ${ }^{11}$ So this study is conducted to compare video head impulse test results among different vestibular lesions and healthy subjects and correlate between video head impulse test and caloric test results.

\section{Methods}

This study was carried out in the Audio vestibular unit at the Al Zahraa University Hospital in the period from 2015 to 2017. The control group included 30 normal healthy subjects with no history 
of vestibular or neurological disorders. They selected from relatives of the patients and our collagues, with mean age $38.33 \pm 10.76$ and $14(46.7 \%)$ female\& $16(53.3 \%)$ male. The study group included 62 patients suffering from dizziness selected randomly from out-patient clinic of Audio vestibular Unite at Al-Zahraa University Hospital with mean age $41.08 \pm 9.94$ and 28 (45.2\%) female \&34 (54.8\%) male. Exclusion criteria: any eye or neck lesions that could limit the vHIT performance.

The study group was subdivided into four subgroups: 19 subjects of VN. Nine subjects of right VN and Ten left VN. They had the following criteria: Attack of acute vertigo lasted at least several hours. No other cranial nerve or central nervous system symptoms or sign.19 subjects with BPPV. Ten cases with right posterior canal BPPV and six cases with left posterior canal BPPV (they had positive DixHallpike maneuver). However supine roll maneuver was positive in 3 cases (lateral canal BPPV). There were ten cases with MD [according to the committee of Hearing and Equilibrium (1995) reviewed at the 2015 AAO-HNSF Annual Meeting the Equilibrium Committee]. They had two or more episodic attacks of vertigo for at least 20 minutes.Audiometrically documented hearing loss. Tinnitus and/or aural fullness.

Fourteen subjects had different central lesions; two cases of cerebral infarction (parietal infarction), three cases of brain mass(two cases with CPA meningioma and a case with jugular foramen schwannoma), Three cases with multiple sclerosis (MS) (all were diagnosed by MRI), four epilepsy cases (were diagnosed by EEG), and two cases of migrainous vertigo. These central cases were diagnosed in neurological clinic and referred to audio-vestibular clinic at $\mathrm{Al}$ Zahraa University Hospital. This subgroup was heterogeneous (made of different central lesions). However, it was representative of patients in neurological clinic. Their central vestibular function was assessed by VNG. All had normal peripheral vestibular function (normal caloric test and abnormal oclumotor tests).

All subjects in this study were submitted to full history taking, neurological and otological examination, pure tone audiometry using AC40 Interacoustic, Immittance testing using MAICO model MI44, and vestibular bedside tests. VNG test battery and bithermal caloric testing were performed using Interacoustic 4 channel model VO425. Caloric UW and directional preponderance were calculated and expressed as a percentage. UW greater than $25 \%$ is significant. ${ }^{12}$
The vHIT was done by using an Interacoustics EyeSeeCam video head impulse system. The subject was instructed to keep staring at an earth-fixed target not less than 1.5 meter in front the subject whiles the head was passively thrust. The thrusts consisted of passive short, sharp head rotations, delivered in an unpredictable direction and magnitude. Recordings were obtained from RT eye for each of the six semicircular canals in all patients (horizontal, left anterior right posterior LARP, right anterior left posterior RALP). A total of 10 accepted head impulses in each direction for each plan were performed (Manufucture manual of Interacoustics EyeSeeCam). Average gain of the VOR responses for each canal and the gain asymmetry were calculated. In healthy individuals the vHIT gain of the vestibulo-ocular reflex is $\geq 0.75$ at $60 \mathrm{~ms}$ Mossman et al. ${ }^{13}$ Also abnormal catch-up saccades were analyzed which occured within a specific time window after the onset of head impulse, for covert saccades it was about 70 to $100 \mathrm{msec}$ to the onset of head motion, (Figure 1) and for overt within $\sim 200$ to $250 \mathrm{msec}$ after the end of head motion. Saccades that fall outside of these windows are not likely to be abnormal catch up saccades. ${ }^{1}$

\section{Statistical plan}

The collected data was introduced to a PC using Statistical package for Social Science (SPSS 20). Student T Test was used to assess the statistical significance difference between two group's means. ANOVA test was used for analysis of variance. Post Hoc test (LSD: Lest significant difference) is used for comparisons of all possible pairs of group means. Chi-Square test was used to test categorical variables. Receiver operating characteristic (ROC) analysis was used in sensitivity and specificity. Area under curve (AUC), area of 1 represent a perfect test, and area of 0.5 represent worthless test. Correlation analysis (using Pearson's method): To assess the strength of association between two quantitative variables. The correlation coefficient denoted symbolically "r" defines the strength (magnitude) and direction (positive or negative) of the linear relationship between two variables.

\section{Results}

Demographic distribution of the studied groups: There was no statistical significant difference between control group and study subgroups as regard of age and gender distribution (Table 1).

Table I Age and gender distribution of the control group and study group

\begin{tabular}{|c|c|c|c|c|c|c|}
\hline \multirow{2}{*}{\multicolumn{2}{|c|}{ Demographic data }} & \multirow{3}{*}{$\begin{array}{l}\text { Control group }(\mathbf{N}=\mathbf{3 0}) \\
38.33 \pm 10.76\end{array}$} & \multirow{3}{*}{$\begin{array}{l}\text { Study group }(\mathbf{N}=\mathbf{6 2}) \\
41.08 \pm 9.94\end{array}$} & \multicolumn{3}{|c|}{ Test of significant } \\
\hline & & & & \multirow{3}{*}{$\begin{array}{l}\text { Test value } \\
\mathrm{tl} .88\end{array}$} & \multirow{3}{*}{$\begin{array}{l}\text { p value } \\
0.063\end{array}$} & \multirow{3}{*}{$\begin{array}{l}\text { Sig } \\
\text { NS }\end{array}$} \\
\hline \multirow{2}{*}{ Age (years) } & Mean \pm SD & & & & & \\
\hline & Range & $20-56$ & $22-60$ & & & \\
\hline \multirow{2}{*}{ Gender } & Female & I4(46.7\%) & $28(45.2 \%)$ & \multirow{2}{*}{$X^{2} 0.19$} & \multirow{2}{*}{0.892} & \multirow{2}{*}{ NS } \\
\hline & Male & $16(53.3 \%)$ & $34(54.8 \%)$ & & & \\
\hline
\end{tabular}

t:Student's t test $\quad X^{2}$ : Chi-square test

\section{vHIT results}

vHIT gain: There was statistical significant difference in vHIT gain between VN subgroup and control group\& other subgroups (in lateral and anterior SCC), there was no significant difference in vHIT results between control and central lesion subgroup (Table 2).

Corrective (refixation) saccades: (overt and covert saccades) were observed in the VN subgroup only. Both overt and covert saccades were detected in 8 patients in lateral canal assessment (Figure 1) and in 2 patients in anterior canal examination. Also corrective saccades were found in 3patients during posterior canal examination. 
Table 2 The vHIT gain results of lateral, anterior and posterior SCCs in control group and study subgroups (affected ears)

\begin{tabular}{|c|c|c|c|c|c|c|c|c|}
\hline \multirow{2}{*}{ vHIT gain } & \multirow{2}{*}{ Control group $(\mathrm{N}=30)$} & \multirow{2}{*}{ VN (N=19) } & \multirow{2}{*}{ BPPV (N=19) } & \multirow{2}{*}{$M D(N=10)$} & \multirow{2}{*}{ Central $(N=\mid 4)$} & \multicolumn{3}{|c|}{ ANOVA } \\
\hline & & & & & & $\mathbf{F}$ & p value & sig \\
\hline $\begin{array}{l}\text { Lateral canal } \\
\text { Mean } \pm S D\end{array}$ & $0.98 \pm 0.1$ & $0.68 \pm 0.26$ & $0.94 \pm 0.07$ & $0.92 \pm 0.09$ & $0.92 \pm 0.11$ & 3.53 & 0.002 & $S$ \\
\hline $\begin{array}{l}\text { Anterior canal } \\
\text { Mean } \pm S D\end{array}$ & $0.88 \pm 0.07$ & $0.69 \pm 0.12$ & $0.84 \pm 0.05$ & $0.80 \pm 0.05$ & $0.84 \pm 0.06$ & 2.87 & 0.026 & $S$ \\
\hline $\begin{array}{l}\text { Posterior canal } \\
\text { Mean } \pm S D\end{array}$ & $0.88 \pm 0.08$ & $0.80 \pm 0.08$ & $0.84 \pm 0.06$ & $0.83 \pm 0.16$ & $0.83 \pm 0.06$ & 1.82 & 0.251 & NS \\
\hline
\end{tabular}
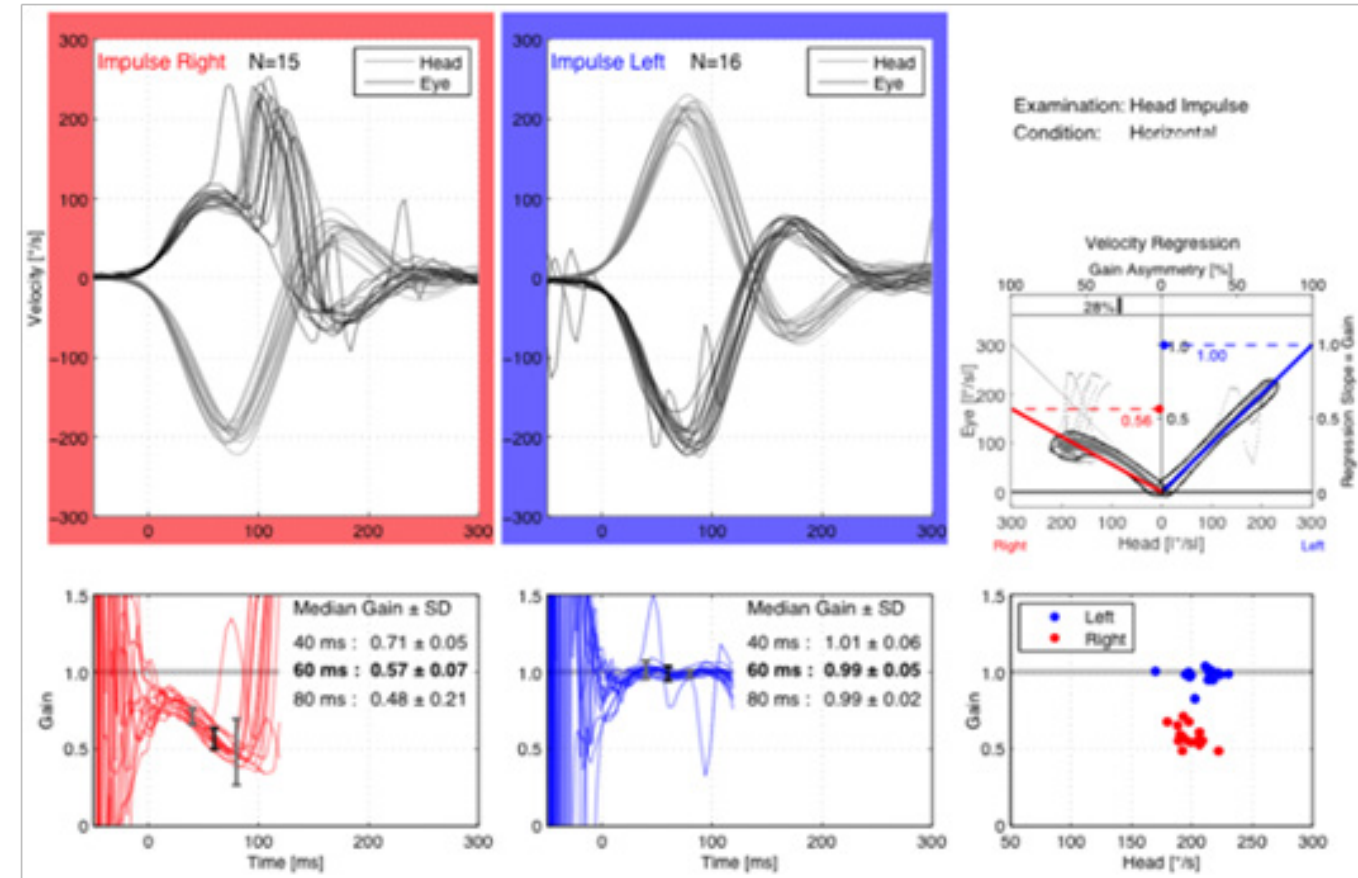

Figure I Example of abnormal vHIT result of subject in VN subgroup. The gain for the left impulses is within the normal range and the right impulses show a reduced gain (0.57). There are covert saccades in the right impulses.

VNG test results: among the 62 subjects in the study group 2 subjects only were found in VN subgroup showed spontaneous nystagmus which was horisontal in direction. The 14 Patients with central lesion subgroup showed abnormal oculomotor tests (low gain \& asymmetric Pursuit and asymmetric OPK). All subjects with prephiral vestibular lesion and healthy controls showed normal oculomoter tests. Among the 62 subjects, $16 / 62$ subjects $(25.8 \%)$ showed upbeating torsional nystagmus (in Dix-Hallpike maneuver), which indicating posterior
SCC BPPV lesions.

\section{Bithermal caloric test result}

Significant caloric (UW\%) was found in all subjects of MD subgroup and VN subgroup (except one case of $\mathrm{VN}$, which was diagnosed as inferior division $\mathrm{VN}$ ). There was statistical significant difference between control group and VN\&MD study subgroups in caloric test results (Table 3 ).

Table 3 The result of caloric test in control group and subgroups of study group

\begin{tabular}{|c|c|c|c|c|c|c|c|c|c|}
\hline \multirow{2}{*}{\multicolumn{2}{|c|}{ Caloric test }} & \multirow{2}{*}{$\begin{array}{l}\text { Control } \\
(\mathrm{N}=30)\end{array}$} & \multirow{2}{*}{$\begin{array}{l}\text { Groupl } \\
\text { (VN) } \\
(\mathrm{N}=19)\end{array}$} & \multirow{2}{*}{$\begin{array}{l}\text { Group II } \\
\text { (BPPV) } \\
\text { (N=19) }\end{array}$} & \multirow{2}{*}{$\begin{array}{l}\text { Group III } \\
(M D)(N=10)\end{array}$} & \multirow{2}{*}{$\begin{array}{l}\text { Group IV } \\
(\text { Central lesion) } \\
(\mathrm{N}=14)\end{array}$} & \multicolumn{3}{|c|}{ ANOVA } \\
\hline & & & & & & & $\mathbf{F}$ & $\mathrm{p}$ value & sig. \\
\hline \multirow[b]{2}{*}{ Caloric } & UW \% & $6.4 \pm 1.81$ & $42.58 \pm 20.4$ & $7.11 \pm 1.52$ & $32.4 \pm 4.25$ & $10.86 \pm 10.35$ & 11.50 & $<0.001$ & $S$ \\
\hline & $\mathrm{Fl} \%$ & $17.03 \pm 2.87$ & $32.58 \pm 8.24$ & $20.47 \pm 8.99$ & $30.9 \pm 7.96$ & $56.36 \pm 9.8$ & 39.52 & $<0.001$ & $S$ \\
\hline test & DP \% & $8.3 \pm 9.04$ & $31.37 \pm 6.81$ & $8.5 \pm 5.4$ & $23.74 \pm 2.73$ & $9.21 \pm 2.61$ & 16.44 & $<0.001$ & $\mathrm{~S}$ \\
\hline
\end{tabular}

\section{Comparison of $\mathrm{vHIT}$ results with caloric test:}

There was statistical significant decrease in vHIT gain in subjects with caloric $\mathrm{UW} \geq 25 \%$, than subjects with caloric $\mathrm{UW}<25 \%$ ( table 4).In VN subgroup there was strong negative correlation between caloric test $(\mathrm{UW} \%)$ results and vHIT gain result in lateral SCC. 
However in other subgroups, there was weak negative correlation between caloric test (UW \%) results and vHIT gain result (table 5 and Figure 2). The highest sensitivity of vHIT was in VN subgroup then MD subgroup, but the highest specificity was in MD subgroup then VN subgroup (Table 6), (Figure 3) and (Figure 4). However, the highest sensitivity and specificity of caloric test were in MD subgroup then VN subgroup.

Table 4 The results of lateral canal vHIT gain in different caloric (UW\%) response in study group

\begin{tabular}{|c|c|c|c|c|c|c|}
\hline \multirow{2}{*}{\multicolumn{2}{|c|}{$\begin{array}{l}\text { Lateral canal } \\
\text { vHIT gain } \\
\text { (in ipsilateral } \\
\text { side of caloric } \\
\text { weakness) }\end{array}$}} & \multirow{2}{*}{$\begin{array}{l}\text { UW\%<25 } \\
(\mathbf{N}=34)\end{array}$} & \multirow{2}{*}{$\begin{array}{l}\text { UW\% } \geq 25 \\
(\mathrm{~N}=\mathbf{2 8})\end{array}$} & \multicolumn{3}{|l|}{ t-test } \\
\hline & & & & $\mathbf{t}$ & p-value & Sig. \\
\hline \multirow{2}{*}{$\begin{array}{l}\text { vHIT } \\
\text { gain }\end{array}$} & Mean $\pm S D$ & $0.93 \pm 0.11$ & $0.77 \pm 0.28$ & \multirow{2}{*}{8.702} & \multirow{2}{*}{0.005} & \multirow{2}{*}{$S$} \\
\hline & Range & $0.6-1.15$ & $0.16-1.12$ & & & \\
\hline
\end{tabular}

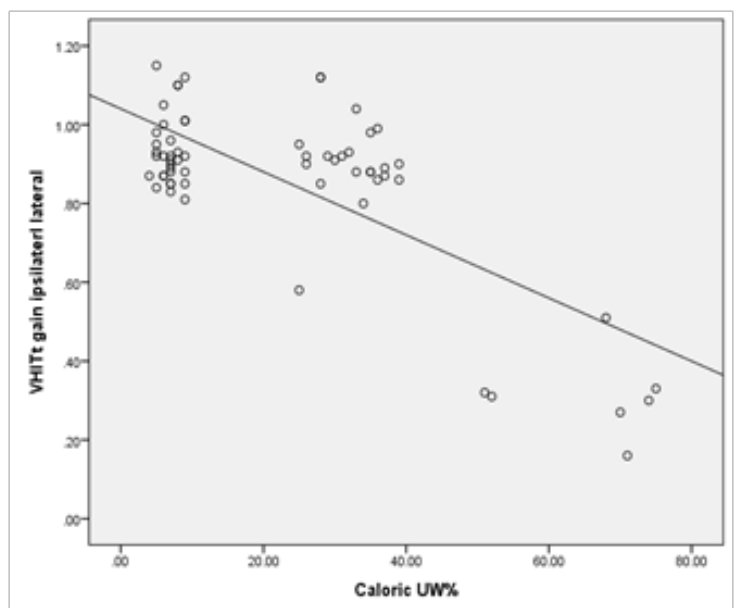

Figure 2 Correlation between vHIT gain and caloric (UW\%) results in VNsubgroup.

Table 5 The correlation between caloric test (UW\%) and vHIT(gain) in different study subgroups

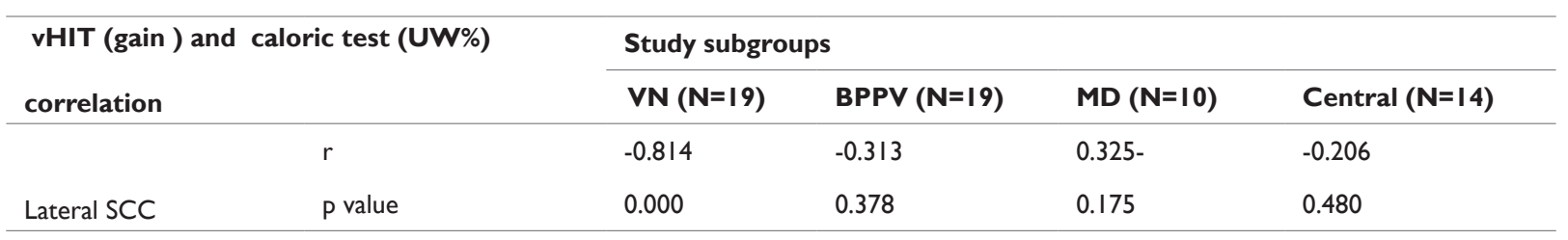

$r=0.8-1$ as strong correlation

$r=0.2-0.39$ as weak correlation Kleinbaum et al.,(1988)

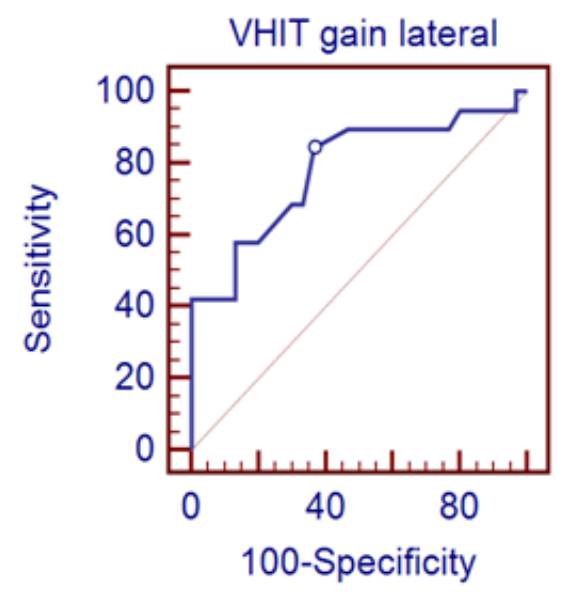

VN
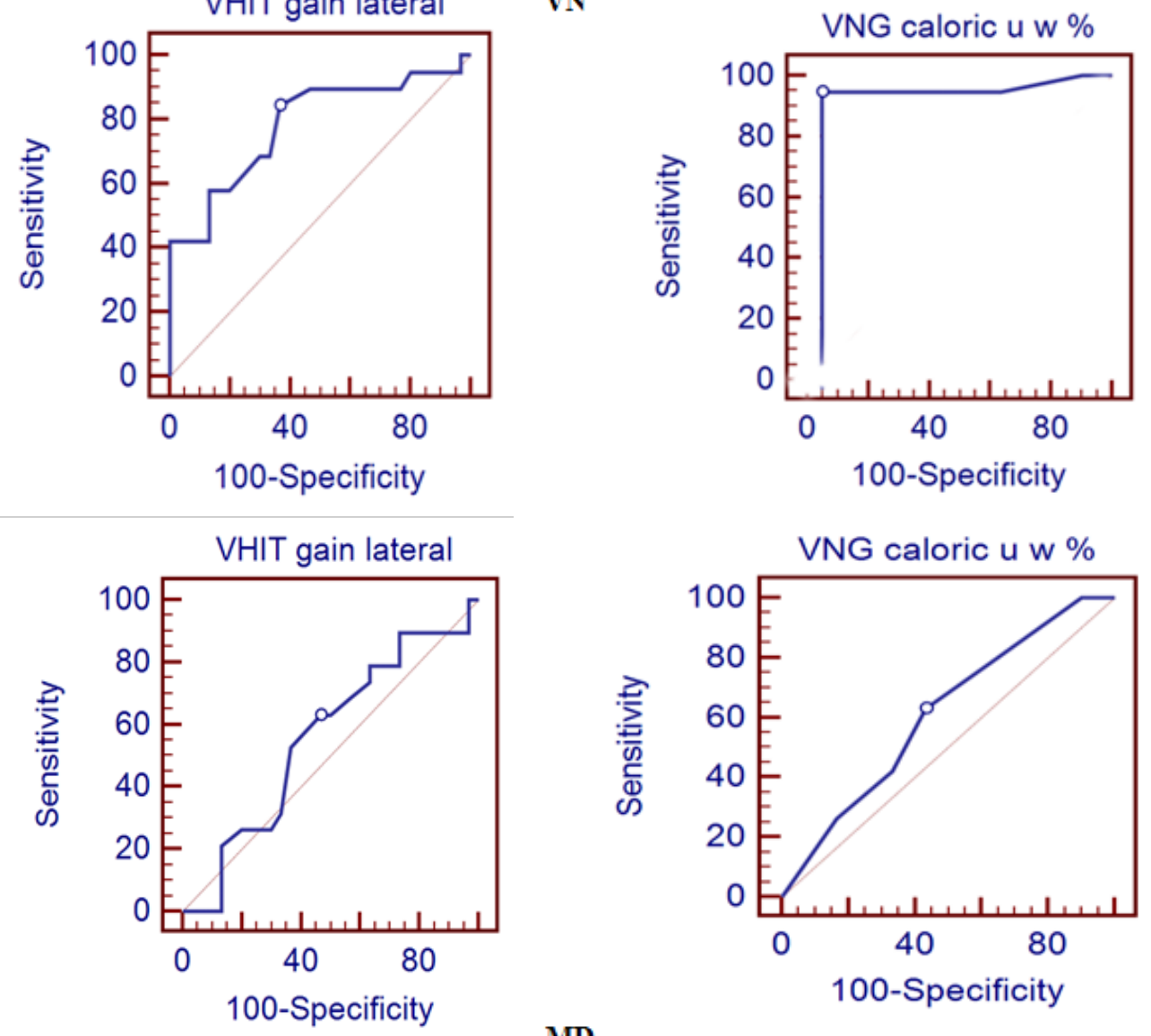

MD

Figure 3 Receiver operating characteristic curve (ROC) of sensitivity and specificity of vHIT and caloric test in VN and MD subgroups.

Citation: Ismail N, Behairy R, Brakat D.Video head impulse test finding in vestibular lesions.J Otolaryngol ENT Res. 20I9; I (I):29-36. 

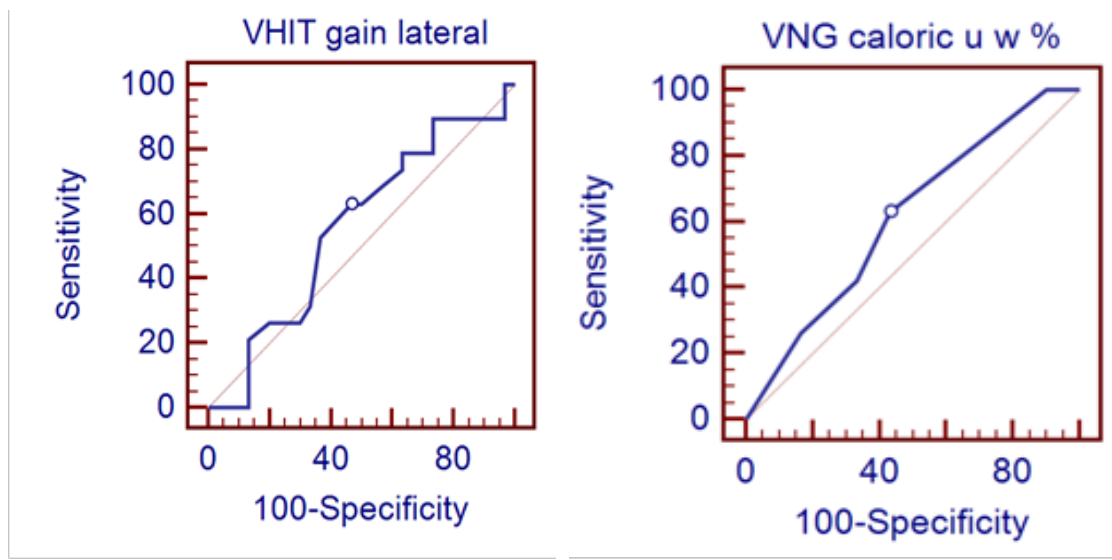

BPPV
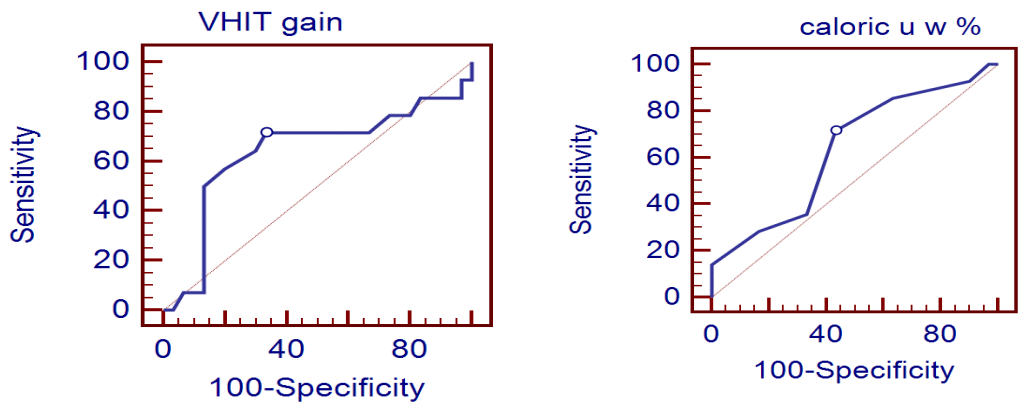

Central lesion

Figure 4 ROC of sensitivity and specificity of vHIT and caloric test in BPPV and central lesion subgroups.

Table 6 Sensitivity and specificity of vHIT gain and caloric test in study subgroups

\begin{tabular}{lllllll}
\hline \multicolumn{2}{c}{ Study subgroups $(\mathbf{n}=62)$} & AUC & p value & sig. & sensitivity & specificity \\
\hline \multirow{2}{*}{ VN } & vHIT gain & 0.783 & 0.0001 & S & 84.21 & 63.33 \\
& Caloric (UW \%) & 0.96 & 0.0001 & S & 94.74 & 99.8 \\
\multirow{2}{*}{ BPPV } & vHIT gain & 0.557 & 0.5038 & NS & 55 & 53.33 \\
& Caloric (UW \%) & 0.612 & 0.163 & NS & 63.23 & 56.67 \\
\multirow{2}{*}{ MD } & vHIT gain & 0.633 & 0.2271 & NS & 63.21 & 86.67 \\
\multirow{2}{*}{ Central } & Caloric (UW \%) & 0.98 & $<0.001$ & S & 99.8 & 99.7 \\
\multirow{2}{*}{ lesion } & vHIT gain & 0.638 & 0.1821 & NS & 71.39 & 59.53 \\
\hline
\end{tabular}

AUC: Area under curve, area of Ipresent a perfect test and area of 0.5 represent worthless test.

Cut off point: Cut off point of $\mathrm{vHIT}=<0.7$, and cut off point of caloric UW=above $25 \%$.

Sensitivity: Ability of the diagnostic test to pick up abnormal cases (true positive): the probability that negative test person does not have the disease.

Specificity: ability of the diagnostic test to pick up normal cases (true negative).

\section{Discussion}

The video head impulse test (vHIT) provides information about each semicircular canal function by quantifying the gain of the VOR and it detects refixation saccades, overt and covert saccades. ${ }^{14}$

In the current study, the study group matched with control group in age and gender with no statistical significant difference between control group and study subgroups (Table 1).
In the present study, there was statistical significance difference between control group and VN subgroup in VHIT gain in lateral and anterior SCCs. Comparing the vHIT gain for the three canals between the four tested subgroups, found significant difference of vHIT gain in VN subgroup with other subgroups (in lateral and anterior SCCs but non-significant in posterior canal) Table 2.

These results were in agreement with Reiss \& Reiss ${ }^{15}$ who found a deficit in vHIT gain in $92 \%$ of cases during the acute phase of 
vestibular neuritis. $\mathrm{Kim}^{16}$ found low vHIT gain during the acute phase of $\mathrm{VN}$. He found that, (VN) mainly affects the superior division of vestibular nerve in $85 \%$ of cases, and inferior vestibular nerve in 15 $\%$.

In the current study the corrective (refixation) saccades (overt and covert saccades) were observed in the $\mathrm{VN}$ subgroup only, both overt and covert saccades were detected in 8 patients in lateral canal assessment (Figure 1) and in 2 patients in anterior canal examination. Also corrective saccades were found in 3patients during posterior canal examination. These results indicated vestibular deficit, VOR was impaired with gain reduction and appearance of refixation saccades. Refixation (catch up) saccades are considered as the cardinal sign of a lesion involving the tested semicircular canal Weber et al. ${ }^{17}$

In the present study there were insignificant gain differences between control, and MD subgroup (affected and unaffected ears) in all three canals (Table 2). None of the Meniere's patients ears (affected or unaffected) had catch-up saccades. However, there was statistical significant difference between subjects of MD subgroup \& VN subgroup and control group in caloric test results (Table 3). Caloric (UW\%) was affected in all subjects of MD subgroup but all had normal vHIT.

These results were in agreement with Kingma \&Wit, ${ }^{18}$ who performed horizontal head impulses using a scleral search coil technique in MD patients. Their results were not significantly different when compared to the healthy side or to healthy subjects. MacDougall et al. ${ }^{5}$ matched the accuracy of search coil technique and vHIT and demonstrated that vHIT and scleral search coil recordings are closely comparable.

Also the current study agree with McGarvie et al., ${ }^{4}$ who reported that many patients with Menière's disease do have normal horizontal canal functionas shown by vHIT, responses to high-acceleration horizontal head rotation, but have reduced or absent caloric responses. It has been suggested that this dissociation between vHIT and caloric results may be an indicator of Menière's disease McCaslin et al. McCaslin et al., explained this dissociation by the cell type theory, as it is known that there are type I and type II hair cells, which are connected to regular and irregular cells. Each cell is activated by a frequency band, which is either low or high frequency. In Meniere's disease, the cells that are responsible for low frequency are the highly affected, and this will explain the more sensitivity of caloric test in MD.

McGarvie et al., ${ }^{4}$ have suggested that this dissociation between vHIT and caloric results may occur because hydrops of Menière's disease dilates the labyrinth and so affects the mechanism by which caloric stimulation activates canal receptors, but that hydrops has little effect on canal-cupula responses to rotation.

However the results of the present study disagree with Blodow et al., ${ }^{1}$ who found abnormal reduced horizontal VOR using vHIT in $45.5 \%$ of the 22 Meniere's patients investigated. Acute and chronic disorders were not differentiated in that study and could be the cause of discrepancy in the prevalence of gain abnormality. In the current study, there was no subject in acute Meniere's attack.

The vHIT showed normal results in patients with BPPV (table2), as this disease is mechanical in origin and not affect the VOR pathway, these results agree with Bhattacharyya et al., ${ }^{19}$ who found that, there were no VOR abnormalities in BPPV patients except if associated with a neurological deficit. Gonzalez \& Perez, ${ }^{20}$ reported that, the
vHIT usually showed normal results in patients with BPPV, as it is less damaging disease (otoconial mechanical displacement) and did not affect VOR pathway.

In the current study, the vHIT and caloric test showed normal results in all subjects with central lesion and there was no statistical significant difference in vHIT and caloric test results between control and central lesion subgroup (Table 2) \& (Table 3). This means that the vestibular lesion pathophysiology in those subjects with different central lesions is central in origin and not associated with peripheral vestibular lesion. However, Blodow et al., ${ }^{21}$ studied the caloric stimulation and video-head impulse testing in vestibular migraine. They found that caloric test was abnormal in $22 \%$ of patients while the vHIT showed horizontal VOR deficit in $9 \%$ of patients. Also ElSherif et al., ${ }^{22}$ reported that $26 \%$ of the vestibular migraine group exhibited abnormal vHIT results in the form of refixation saccades with normal VOR gain (18\%), and low VOR gain with refixation saccades in $(7.5 \%)$. They reportd that the presence of covert saccades despite normal VOR gain is a correction of eye drifts to the target position and it has been suggested that the presence of refixation saccades with normal VOR gain is part of the process of aging of the vestibular system. $^{23}$

Yollu et al., ${ }^{24}$ reported significantly higher covert saccades in migraine patients compared to healthy controls, and suggested that these saccades were associated with the connection between the trigeminal nerve and the vestibular nuclei.

Also Newman-Toker et al., ${ }^{25}$ reported that, between $9 \%$ and $20 \%$ of positive vHIT results have been reported in patients with acute cerebellar or brainstem strokes. Although exact neuroanatomical correlates remain unknown. Kremmyda et al., ${ }^{26}$ study has indicated the floccules to be a potential candidate of this positive vHIT results. In addition, abnormal vHIT has been reported in another patient with a unilateral circumscribed cerebellar lesion near the floccules. ${ }^{27}$

The subjects with caloric weakness in this study subdivided to subjects with caloric UW\% $<25$ and subjects with caloric test UW\% $\geq 25$. There was statistical significant decrease in vHIT gain in subjects with caloric $\mathrm{UW} \geq 25 \%$, than subjects with caloric $\mathrm{UW}<25 \%$ (lateral canal vHIT gain in ipsilateral side of caloric weakness) (Table 4).

This result was in agreement with Bartolomeo et al., ${ }^{6}$ who found the vHIT gain decreased to abnormal value when the caloric deficit is between 40 and $65 \%$ in case of $\mathrm{VN}$.

In the current study, $\mathrm{VN}$ subgroup had strong negative correlation between caloric test (UW \%) and vHIT gain results in lateral SCC. This negative correlation between caloric test (UW \%) and vHIT gain results was weak in other subgroups (Table 5) and (Figure 2).

This result was in agreement with previous work of Park et al., ${ }^{28}$ who aimed at correlating its vHIT findings with those of the caloric test in 38 Meniere's patients and they have shown a clear difference. This means that, normal vHIT results could be not associated with normal caloric test in some cases, because caloric UW below $40 \%$ can produce normal vHIT. Also normal caloric test could be not associated with normal vHIT in some cases, because posterior SCC lesion with normal lateral SCCs would produce normal caloric responses and abnormal vertical vHIT.

In the current study the caloric test had the highest sensitivity and specificity than vHIT in all subgroups except central lesion subgroup (they are almost equal) (Table 6) (Figure 2) and (Figure 3). 
This lack of vHIT sensitivity comparing with caloric tes sensitivity has previously been reported by Perez-Ferna'ndez et al., ${ }^{29}$ they showed in 23 patients with vestibular neuritis, that specificity of the head impulse test was $91 \%$ and the sensitivity was $45 \%$.

Bartolomeo et al., ${ }^{6}$ found the sensitivity of vHIT increased up to $86.7 \%$ and specificity to $100 \%$ when the caloric deficit is between 40 and $65 \%$ in case of VN..$^{30-33}$ The sensitivity of vHIT increased to 100 $\%$ if caloric deficit is more than $65.2 \%$. However, in normal vHIT, caloric test is mandatory to rule out a peripheral vestibular lesion.

\section{Conclusion}

Increased sensitivity of vHIT to large unilateral peripheral vestibular lesions. Caloric testing was a more sensitive measure than vHIT in peripheral vestibular lesions but in central lesion they are almost equal. Strong negative correlation between caloric test (UW\%) and vHIT gain results in lateral SCC was found in VN lesion. It was weak in other vestibular lesions. vHIT can differentiate between central and peripheral vertigo where it is normal in all central vestibular lesions so it is recommended to be used in emergency room in cases of acute vertigo as a triage test. vHIT should be included in the vestibular assessment protocol for adult \&children.

\section{Acknowledgment}

None.

\section{Conflicts of interest}

The author declares there is no conflict of interest.

\section{References}

1. Blodow A, Pannasch S, Walther LE. Detection of isolated covert saccades with the video head impulse test in peripheral vestibular disorders. Auris Nasus Larynx. 2013;40:348-351.

2. McCaslin D, Jacobson G, Bennett M, et al. Predictive Properties of the Video Head Impulse Test: Measures of Caloric Symmetry and SelfReport Dizziness Handicap. Ear and Hearing. 2014;35(5):185-191.

3. Luiz P, Carlos F. The video head impulse test. ActaOto-Laryngologica. 2014;134:1245-1250.

4. Heuberger M, Lehnen N, Luis L et al. Clinical utility and practical interpretation of the video head impulse test. ENT \& Audiology News. $2015 ; 24(5)$.

5. MacDougall HG, Weber KP, McGarvie LA, et al. The video head impulse test: diagnostic accuracy in peripheral vestibulopathy. Neurology. 2009;73:1134-1141.

6. Bartolomeo M, Biboulet R, Pierre G, et al. Value of the video head impulse test in assessing vestibular deficitsfollowing vestibular neuritis. Euro arch oto-rhino-laryngol. 2014;271(4):681-688.

7. McCaslin DL, Rivas A, Jacobson GP, et al. The dissociation of video head impulse test (vHIT) and bithermal caloric test results provide topological localization of vestibular system impairment in patients with “definite” Meniere's disease. Am J Audiol. 2015;24(1):1-10.

8. Manzari L, Burgess AM, MacDougall HG, et al. Rapid fluctuations in dynamic semicircular canal function in early Ménière's disease. Eur Arch Otorhinolaryngol. 2011;268:637-639.

9. Migliaccio AA, Cremer PD. The 2D modified head impulse test: a 2D technique for measuring function in all six semi-circular canals. Journal of Vestibular Research. 2011;21(4):227-234.

10. Machner B, Sprenger A, Fullgraf H, et al. Video-based head impulse test Importance for routine diagnostics of patients with vertigo. Nervenarzt. 2013;84(8):975-983.
11. Jorns-Haderli M, Straumann D, Palla A. Accuracy of the bedside head impulse test in detecting vestibular hypofunction. J Neurol Neurosurg Psychiatry. 2007;78(10):1113-1118.

12. Barin K. Interpretation and usefulness of caloric testing. In: Jacobson GP, Shepard NT, editors. Balance Function Assessment and Management. San Diego: Plural Publishing. 20111; pp. 229-252.

13. Mossman B, Mossman S, Purdie G, et al. Age dependent normal horizontal VOR gain of head impulse test as measured with videooculography. J Otolaryngology Head Neck Surg. 2015;44:29

14. Ulmer E, Chays A. Curthoys and Halmagyi Head Impulse test: an analytical device. Ann Otolaryngol Chir Cervicofac. 2005;122(2):84-90.

15. Reiss M, Reiss G. Vestibular neuritis: is there any evidence of an asymmetric distribution? Eur Arch Otorhinolaryngol. 2012; 269:10911094.

16. Kim JS. Inferior vestibular neuritis. J Neurol. 2015;259(8):1553-1560.

17. Weber KP, Aw ST, Todd MJ, et al. Head impulse test in unilateral vestibular loss: vestibulo-ocular reflex and catch-up saccades. Neurology. 70(6):454-463

18. Kingma CM, Wit HP. Asymmetric vestibular evoked myogenic potentials in unilateral Menière patients. Eur Arch Otorhinolaryngol. 2011;268(1):57-61.

19. Bhattacharyya N, Baugh RF, Orvidas L. Clinical practice guideline: benign paroxysmal positional vertigo. Otolaryngol Head Neck Surg. 2017;156(3_suppl):S1-S47.

20. González del Pino B, Pérez Fernández N. Disability in patients with benign paroxysmal positional vertigo with posterior semicircular canal involvement. Acta Otorrinolar. 2009;54(6):401-408.

21. Blodow A, Heinze M, Boris M, et al. Caloric stimulation and video head impulse test in Ménière's disease and vestibular migraine. Acta otoLaryngologica. 2014;134(12):1239-1244.

22. ElSherif M, Reda MI, Saadallah H, et al. Video head impulse test (vHIT) in migraine dizziness. J Otol. 2018;13(2):65-67.

23. Anson ER, Bigelow RT, Carey JP, et al. Aging increases compensatory saccade amplitude in the video head impulse test. Front Neurol. 2016;7:113.

24. Yollu U, Uluduz DU, Yilmaz M, et al. Vestibular migraine screening in a migraine diagnosed patient population, and assessment of vestibulocochlear function. Cl Otolaryngol. 2016;42(2):225e233.

25. Newman-Toker DE, Kattah JC, Alvernia JE et al. Normal head impulse test differentiates acute cerebellar strokes from vestibular neuritis. Neurology. 2008;70(24 pt 2):2378-2385.

26. Kremmyda O, Kirchner H, Glasauer S, et al. False-positive head-impulse test in cerebellar ataxia. Front Neurol. 2012;3:162.

27. Park HK, Kim JS, Strupp M. Isolated floccular infarction: impaired vestibular responses to horizontal head impulse. $J$ Neurol. 2013;260(6):1576-1582.

28. Park HJ, Lee IS, Shin JE, et al. Frequency-tuning characteristics of cervical and ocular vestibular evoked myogenic potentials induced by air-conducted tone bursts. Clinical Neurophysiology. 2010;121(1):85-89.

29. Pérez-Fernández N, Gallegos-Constantino V, Barona-Lleo L, et al. Clinical and video-assisted examination of the vestibulo-ocular reflex: a comparative study. Acta Otorrinolaringol Esp. 2012;63(6):429-435.

30. Halmagyi GM, Weber KP, Curthoys IS. The video head impulse test: Vestibular function after acute vestibular neuritis. Restor Neurol Neurosci. 2010;28(1):37-46.

31. Kleinbaum D, Kupper LL, Muller KE. Applied Regression Analysis and Other Multivariable Methods. PWS-Kent, Boston, MA, 2 ${ }^{\text {nd }}$ edition, 1988. 
32. Sadeghi SG, Chacron MJ, Taylor MC, et al. Neural variability, detection thresholds, and information transmission in the vestibular system. $J$ Neurosci. 2007;27(4):771-781.
33. Wuyts F, Boniver R. Normative data in ENG and VNG. B-ENT. 2008;4(Suppl 8):45-47. 